\title{
Identification and Selection of Entomopathogenic Fungi as Biocontrol Agents for Aphis gossypii from South Sumatra
}

\author{
SITI HERLINDA*, CHANDRA IRSAN, REKA MAYASARI, AND SELLY SEPTARIANI \\ Department of Plant Pests and Diseases, Faculty of Agriculture, Universitas Sriwijaya, \\ Jalan Raya Palembang-Prabumulih, km 32, Ogan Ilir, Inderalaya 30662, South Sumatra, Indonesia
}

\begin{abstract}
Aphid, Aphis gossypii is a vector of curly virus disease. The damage of chili due to its feeding is only $35 \%$ and it can achieved $100 \%$ if the damage caused by the aphid as a vector. The objectives of this research were to explore, to isolate, to identify, and to select entomopathogenic fungi as biocontrol agents for A. gossypii. The fungi were explored using insect bait in soil and collected infected insects from South Sumatra, Indonesia. Then, the fungi were isolated and identified, and finally the bioefficacy tests were done using $1 \times 10^{6}$ conidia $\mathrm{mL}^{-1}$ against the third instar of A. gossypii. The explorations found 25 isolates of enthomopathogenic fungi consisting 10 isolates of Beauveria bassiana and 15 isolates of Metarhizium anisopliae. Selection of the fungi isolates on the aphid nymphs showed that isolate BPM isolated from Pseudoplusia chalcites caused the highest mortality rate $(80.80 \%)$, while the lowest $(47.20 \%$ ) was caused by the isolate BAgTb isolated from A. gossypii. The shortest time needed to produce $50 \%$ mortality (Lethal Time ${ }_{50}$ ) was 2.54 days (isolate of Chrysodeixis chalcites from Muarasiban). The longest time (3.66 days) was produced by isolate of Tenebrio molitor from Tanjung Raja.
\end{abstract}

Key words: Aphis gosypii, Beauveria, Metarhizium, fungi

The most important pest for chili is Aphis gossypii, which is the vector of curly virus disease Aphid, Aphis gossypii is a vector of curly virus disease. The damage of chili due to its feeding is only $35 \%$ and it can achieved $100 \%$ if the damage caused by the aphid as a vector (Fuller et al. 1999). A. gossypii is a carrier for 76 viruses attacking various host plants (Satar et al. 1999) and has been reported resistant to various insecticides (Wang et al. 2002).

It is crucial to identify an alternative control that is relatively safer for both agricultural product and environmental health. Biological control is the main component of integrated pest management (IPM) that is a safer pest control than other control methods (Lopes et al. 2009). Biological control is needed for green consumers in the world who prefered pesticide free agricultural products. This can be achieved by controlled biologically of the vector insects using natural enemies, such as entomopathogen.

Beauveria bassiana and Metarhizium anisopliae are common soil-borne entomopathogenic fungi that occur worldwide. B. bassiana cause a disease known as the white muscardine disease because infected insects covered with a layer of white mold (Alves et al. 2002; Klinger et al. 2006) and the green muscardine disease for $M$. anisopliae (Santiago et al. 2001). Both fungi attack the immature and adult stages of several insect orders, such as Hemiptera (Liu et al. 2002) and Diptera (Moraga et al. 2006). In order to develop successful biological control, a basic research is needed to find entomopathogenic fungi which are most pathogenic againts the vector, A. gossypii. Therefore, the objectives of this research were to explore, to isolate, to identify, and to select entomopathogenic fungi as biocontrol agents for A. gossypii.

*Corresponding author, Phone +62-711-580663, Fax:+62-711-580276, Email: sherlinda_hpt_fp@unsri.ac.id

\section{MATERIALS AND METHODS}

Exploration of Entomopathogenic Fungi. Entomopathogenic fungi exploration was done by using two methods to obtain many species or strains of the fungi. The first method by collecting aphid nymphs and adults, larvae of Lepidoptera, Hemiptera, and other insect ordo that were sick or dead due to fungus infection (Herlinda et al. 2008). The infected insects that showed symptoms of dry body and the presence of conidia and fungal conidia, white or green body of the larvae were isolated or purified. Surveys to explore the fungi were carried out five times on each location. Then, the fungus-infected insects were isolated in the laboratory at a cabinet of laminar air flow that had been sterilized with $70 \%$ alcohol.

The second method of fungus exploration was to use insect as bait following method of Hashim and Azwana (2003). The insect used was third instar of Tenebrio molitor (hongkong caterpillar) that had been newly molting. Soil used to trap the fungi was taken by purposive sampling from forests in South Sumatra. The soil sample was taken by digging at a depth of $50-10 \mathrm{~cm}$, brought to the laboratory as much as $400 \mathrm{~g}$, and then it was put into a plastic tray $(13 \times 13$ $\mathrm{x} 10 \mathrm{~cm}^{3}$ ). The hongkong caterpillars were immersed $0.5 \mathrm{~cm}$ deep in the soil, and 20 larvae of the caterpillars were put in bottom of the tray. This treatment was repeated 20 times. Then, the tray was covered with a piece of black cloth that had been moistened. Three days later, the infected caterpillars were examined and isolated in the laboratory.

Isolation and Identification of Entomopathogenic Fungi. Isolation of entomopathogenic fungi used methods of Herlinda et al. (2006). The fungus-infected insects and caterpillars were sterilized with $1 \%$ sodium hypochlorite or $70 \%$ alcohol for three minutes. Then insects were rinsed with sterile water three times, and dried on top of sterile filter paper. Then, they were placed in a petri dish (diameter $9 \mathrm{~cm}$ ) containing moist sterile paper and incubated to stimulate 
conidial germination. Fungi were isolated, cultured on Saborroud Dextrose Agar (SDA) medium, and incubated for seven days at $25-27^{\circ} \mathrm{C}$ and relative humidity $80-85 \%$. Then, a pure culture fungus was identified by using reference of Toledo et al. (2010).

The isolate was grown on slants of SDA medium supplemented with chitin from the small mole cricket, kept in $1.5 \times 13 \mathrm{~cm}$ glass test tubes, and incubated for 7 days. The fungal spores were harvested from the slant culture, and each $1 \mathrm{~g}$ medium of the isolate was separately suspended in $9 \mathrm{~mL}$ water. Conidial density was calculated after analysis of a 1 $\mathrm{mL}$ sample of the suspension in a haemocytometer.

Conidial germination as a measure of viability was obtained by spreading $1 \times 10^{6}$ propagules in $100 \mu \mathrm{L}$ on glucose yeast agar (GYA) medium. The suspension was incubated at room temperature for $24 \mathrm{~h}$. To calculate conidial viability per unit volume, total counts estimated with the haemacytometer were multiplied by the percentage of germination.

Selection of Entomopathogenic Fungi as Biocontrol Agents. After culturing isolates of the fungi, A. gossypii was also cultured on the chili to get the available colony that would be used to entomopathogenic fungi selection. The selection was done using method of Herlinda et al. (2008). Conidia of the fungal isolates were used by dripping topically $10 \mu \mathrm{L}$ fungal suspension (density of $1 \times 10^{6}$ conidia $\mathrm{mL}^{-1}$ ) on the third instar of $A$. Gossypii. In this experiment, each isolate (Table 1) was inoculated on 25 newly moltingthird instar of $A$. gossypii and repeated five times. Nymphs that had been exposed to the fungus conidia were subsequently maintained in plastic cylinders (diameter $9 \mathrm{~cm}$ and height $30 \mathrm{~cm}$ ) covered with cloth. In the cylinders, there was a pot (diameter $9 \mathrm{~cm}$ ) of chili growth. Every $6 \mathrm{~h}$ during the nymph stage, the number of dead nymph were recorded, while the number of nymphs growing to be adults were also recorded daily until all the nymphs became adult.

Data Analysis. The difference of mortality data and adult percent emerging were analyzed using analysis of variance, with the Tukey test. Time of nymph death was analyzed to determine the $\mathrm{LT}_{50}$ using probit analysis and also calculated by using SAS-STAT program.

\section{RESULTS}

Isolates of Entomopathogenic Fungi. Two species of entomopathogenic fungi from South Sumatra were identified, B. bassiana and M. anisopliae. B. bassiana consisted of 10 isolates, whereas M. anisopliae were 15 isolates (Table 1). The fungi could be found in lowland and highland areas of South Sumatra, however they were more found in lowland areas than in highlands. Exploration method by dipping bait insecs in the soil was more effective than collecting infected insects from the field. M. anisopliae isolates more often found during survey than $B$. bassiana isolates.

Table 1 Entomopathogenic fungi isolates collected from South Sumatra

\begin{tabular}{|c|c|c|c|}
\hline Isolate codes & Source host insects & Origins & Exploration methods \\
\hline \multicolumn{4}{|c|}{ Lowland areas } \\
\hline $\mathrm{BAgTb}$ & Aphis gossypii & Talang Buruk & Collection of infected insects \\
\hline $\mathrm{BNIPTr}$ & Nilaparvata lugens & Pantura & Collection of infected insects \\
\hline BTmSo & Tenebrio molitor & Soak & Bait insects in soil \\
\hline $\mathrm{BTmTb}$ & Tenebrio molitor & Talang Buruk & Bait insects in soil \\
\hline MaAgIn & Aphis gossypii & Inderalaya & Collection of infected insects \\
\hline MaLaIn & Leptocorisa acuta & Inderalaya & Collection of infected insects \\
\hline MAgIn & Aphis gossypii & Inderalaya & Collection of infected insects \\
\hline MLaPTr & Leptocorisa acuta & Pantura & Collection of infected insects \\
\hline $\mathrm{MTmBb}$ & Tenebrio molitor & Bukit besar & Bait insects in soil \\
\hline MTmIn & Tenebrio molitor & Inderalaya & Bait insects in soil \\
\hline MTmGb & Tenebrio molitor & Gelumbang & Bait insects in soil \\
\hline MTmKt & Tenebrio molitor & Kenten & Bait insects in soil \\
\hline MTmTk & Tenebrio molitor & Talang Kelapa & Bait insects in soil \\
\hline $\mathrm{MTmTr}$ & Tenebrio molitor & Tanjung Raja & Bait insects in soil \\
\hline \multicolumn{4}{|c|}{ Highland areas } \\
\hline BLePd & Lipaphis erysimi & Pagardin & Collection of infected insects \\
\hline BPM & Chrysodeixis chalcites & Muarasiban & Collection of infected insects \\
\hline $\mathrm{BPcPd}_{1}$ & Chrysodeixis chalcites & Pagardin & Collection of infected insects \\
\hline $\mathrm{BPcPd}_{2}$ & Chrysodeixis chalcites & Pagardin & Collection of infected insects \\
\hline BTmPd & Tenebrio molitor & Pagardin & Bait insects in soil \\
\hline $\mathrm{BCcC}$ & Chrysodeixis chalcites & Curup & Collection of infected insects \\
\hline MAgPd & Aphis gossypii & Pagardin & Collection of infected insects \\
\hline MTmBk & Tenebrio molitor & Bedeng Kresek & Bait insects in soil \\
\hline MTmJr & Tenebrio molitor & Jarai & Bait insects in soil \\
\hline $\mathrm{MTmKj}$ & Tenebrio molitor & Kerinjing & Bait insects in soil \\
\hline MTmMs & Tenebrio molitor & Muarasiban & Bait insects in soil \\
\hline
\end{tabular}


Table 2. Conidial density of Beauveria bassiana and Metarhizium anisopliae isolates

\begin{tabular}{|c|c|c|}
\hline \multirow{2}{*}{ Isolate codes } & \multicolumn{2}{|c|}{ Conidial density $\left(\times 10^{6}\right.$ conidia $\left.\mathrm{mL}^{-1}\right)$} \\
\hline & Range & Mean \pm SE \\
\hline \multicolumn{3}{|c|}{ Beauveria bassiana } \\
\hline BAgTb & $36.60-37.40$ & $37.00 \pm 0.40$ ef \\
\hline $\mathrm{BCcC}$ & $21.55-22.23$ & $21.87 \pm 0.34 \mathrm{abc}$ \\
\hline BLePd & $43.30-45.15$ & $43.98 \pm 1.02 \quad f$ \\
\hline BN1PTr & $20.60-43.35$ & $21.53 \pm 0.54 \mathrm{abc}$ \\
\hline BPM & $37.15-59.60$ & $45.39 \pm 12.36 \mathrm{f}$ \\
\hline $\mathrm{BPcPd}_{1}$ & $24.60-27.52$ & $26.25 \pm 1.49 \mathrm{~cd}$ \\
\hline $\mathrm{BPcPd}_{2}$ & $20.60-22.83$ & $21.61 \pm 1.13 \mathrm{abc}$ \\
\hline BTmPd & $42.17-43.65$ & $42.73 \pm 0.80 \quad \mathrm{f}$ \\
\hline BTmSo & $17.23-21.23$ & $19.85 \pm 2.27 \mathrm{ab}$ \\
\hline $\mathrm{BTmTb}$ & $20.40-24.52$ & $22.81 \pm 2.15 \mathrm{abc}$ \\
\hline \multicolumn{3}{|c|}{ Metarhizium anisopliae } \\
\hline MaAgIn & $19.08-20.25$ & $19.63 \pm 0.59 \quad \mathrm{a}$ \\
\hline MAgIn & $37.40-38.00$ & $37.78 \pm 0.33$ ef \\
\hline MAgPd & $43.95-44.85$ & $44.46 \pm 0.46 \quad \mathrm{f}$ \\
\hline MaLaIn & $19.37-19.45$ & $19.38 \pm 0.04 \quad \mathrm{a}$ \\
\hline MLaPtr & $17.88-20.90$ & $19.74 \pm 1.63$ \\
\hline $\mathrm{MTmBb}$ & $18.75-20.45$ & $19.36 \pm 0.95 \quad \mathrm{a}$ \\
\hline $\mathrm{MTmBk}$ & $38.05-39.20$ & $38.72 \pm 0.59$ ef \\
\hline MTmGb & $29.50-34.37$ & $31.98 \pm 2.44 \quad \mathrm{f}$ \\
\hline MTmIn & $35.70-38.47$ & $38.96 \pm 3.53$ ef \\
\hline MTmJr & $36.87-38.70$ & $37.62 \pm 0.96$ ef \\
\hline $\mathrm{MTmKj}$ & $42.45-44.70$ & $44.06 \pm 1.40 \quad \mathrm{f}$ \\
\hline $\mathrm{MTmKt}$ & $27.65-23.35$ & $25.05 \pm 0.32 \mathrm{bc}$ \\
\hline MTmMs & $42.87-43.42$ & $43.10 \pm 0.29 \quad \mathrm{f}$ \\
\hline MTmTk & $18.00-18.63$ & $18.36 \pm 2.29 \mathrm{a}$ \\
\hline MTmTr & $38.37-44.27$ & $41.98 \pm 3.16 \quad \mathrm{f}$ \\
\hline
\end{tabular}

Data in the same column followed by the same letter showed they were not significantly different (HSD test, P 0.05 ).

\section{Conidial Density and Viability of Entomopathogenic}

Fungi. B. bassiana and $M$. anisopliae isolates had very dense conidia, but the trend of conidial density of $B$. bassiana isolates was significantly higher compared to $M$. anisopliae isolates (Table 2). The highest conidial density of entomopathogenic fungi reached $45.39 \times 10^{6}$ conidia $\mathrm{mL}^{-1}$ that was found on B. bassiana isolates coded BPcM, the lowest found on MTmTk isolate of M. anisopliae $\left(18.36 \times 10^{6}\right.$ conidia $\mathrm{mL}^{-1}$ ).

The highest conidial viability of entomopathogenic fungi reached $47.50 \%$ with a $41.87 \%$ average viability that was found in B. bassiana isolates coded by BPcM (Table 3). The lowest conidial viability averaged of $11.90 \%$ found on $M$. anisopliae isolates coded by MTmBb. The conidial viability of $B$. bassiana isolates tended significantly higher than those of M. anisopliae isolates.

Virulence Isolates of Entomopathogenic Fungi. Twenty five isolates were selected to determine the most virulent isolate againts $A$. gossypii nymphs. The results showed that all $B$. bassiana and $M$. anisopliae isolates were pathogenic to the nymphs of $A$. gossypii causing mortalities between 42.40 and $80.80 \%$ (Table 4 ). The most virulent isolate was BPM of $B$. bassiana isolate causing an average of $80.80 \%$ mortality, and the two least ones were BAgTb of B. bassiana isolate and MLaPtr of M. anisopliae isolate. A. gossypii mortality caused
Table 3. Conidial viability of Beauveria bassiana and Metarhizium anisopliae isolates

\begin{tabular}{|c|c|c|}
\hline \multirow{2}{*}{ Isolate codes } & \multicolumn{2}{|c|}{ Percentage of conidial viability (\%) } \\
\hline & Range & Mean \pm SE \\
\hline \multicolumn{3}{|c|}{ Beauveria bassiana } \\
\hline $\mathrm{BAgTb}$ & $14.30-24.20$ & $20.67 \pm 5.52$ \\
\hline $\mathrm{BCcC}$ & $19.89-33.29$ & $25.20 \pm 7.12$ abcdef \\
\hline BLePd & $20.00-28.10$ & $25.20 \pm 4.51$ abcdef \\
\hline BNIPTr & $14.80-20.30$ & $16.80 \pm 3.04$ \\
\hline BPM & $38.10-47.50$ & $41.87 \pm 4.97$ \\
\hline $\mathrm{BPcPd}_{1}$ & $22.72-34.78$ & $28.37 \pm 6.07 \mathrm{abcdef}$ \\
\hline $\mathrm{BPcPd}_{2}$ & $14.83-31.37$ & $21.50 \pm 8.72$ abcde \\
\hline BTmPd & $12.50-19.40$ & $16.01 \pm 3.45$ \\
\hline BTmSo & $29.03-36.40$ & $36.58 \pm 3.79$ \\
\hline BTmTb & $26.30-40.90$ & $31.5 \pm 8.16$ bcdef \\
\hline \multicolumn{3}{|c|}{ Metarhizium anisopliae } \\
\hline MaAgIn & $5.49-21.37$ & $13.15 \pm 7.95$ \\
\hline MAgIn & $10.50-15.15$ & $13.15 \pm 2.39$ \\
\hline MAgPd & $15.40-23.50$ & $18.83 \pm 4.19 \quad$ abcd \\
\hline MaLaIn & $9.69-18.28$ & $14.80 \pm 4.52$ \\
\hline MLaPtr & $15.70-21.53$ & $16.80 \pm 2.92$ \\
\hline MTmBb & $8.71-14.47$ & $11.9 \pm 2.93$ \\
\hline MTmBk & $10.80-17.80$ & $14.87 \pm 3.64$ \\
\hline MTmGb & $25.00-29.80$ & $28.13 \pm 2.72$ abcdef \\
\hline MTmIn & $20.70-34.60$ & $26.09 \pm 7.46$ abcdef \\
\hline MTmJr & $14.30-24.20$ & $20.67 \pm 5.52 \quad \mathrm{abcd}$ \\
\hline MTmKj & $20.00-27.02$ & $23.61 \pm 3.51$ abcdef \\
\hline MTmKt & $28.00-43.50$ & $32.21 \pm 7.89$ \\
\hline MTmMs & $20.00-27.60$ & $21.00 \pm 6.16 \quad \mathrm{abcd}$ \\
\hline MTmTk & $15.68-26.71$ & $21.70 \pm 5.58$ abcde \\
\hline MTmTr & $31.43-53.30$ & $39.91 \pm 11.7$ \\
\hline
\end{tabular}

Data in the same column followed by the same letter showed they were not significantly different (HSD test, P 0.05 ).

by BPM isolate was significantly different from BAgTb and MLaPtr isolates. BPcM isolate was isolated from Chrysodeixis chalcites in highland areas, BAgTb isolate from Aphis gossypii, and MLaPtrisolate from Leptocorisa acuta. Both of the BAgTb and MLaPtr isolates were from lowland areas. The level of $A$. gossypii mortality caused by $B$. bassiana treatment tended to be higher than those of $M$. anisopliae treatment.

All B. bassiana and $M$. anisopliae isolates were able to infect $A$. gossypii nymphs and almost had low value of lethal time median $\left(\mathrm{Lt}_{50}\right)$. The time median when death occured differed among isolates and it varied between 2.54 and 3.66 days. (Table 5). The result indicated that BPM isolate of $B$. bassiana had the lowest $\mathrm{LT}_{50}$ value (2.54 days) againts $A$. gossypii nymphs, while MTmTr isolate of $M$. anisopliae was the highest one (3.66 days).

\section{DISCUSSION}

In this study, exploration methods that were able to find entomopathogenic fungi were deeping insect bait in the soil and collecting the infected insects from the fields. Preliminary survey following method of Feng et al. (2007) had tried to find the fungal conidia of entomopathogen from air using sticky cards but they were unable to be found. The fungi were easier to be found from the soil compared to infected insects from the fields. Herlinda et al. (2008) found that the entomopathogenic fungi obtained from infected 
Table 4 Mortality of Aphis gossypii nymph exposed to conidia of Beauveria bassiana and Metarhizium anisopliae at a concentration of $10^{6}$ conidia $\mathrm{mL}^{-1}$

\begin{tabular}{|c|c|c|}
\hline \multirow{2}{*}{ Isolate codes } & \multicolumn{2}{|c|}{ Nymph mortality (\%) } \\
\hline & Range & Mean $\pm \mathrm{SE}$ \\
\hline \multicolumn{3}{|c|}{ Beauveria bassiana } \\
\hline $\mathrm{BAgTb}$ & $32-60$ & $42.40 \pm 13.44 \mathrm{a}$ \\
\hline $\mathrm{BCcC}$ & $36-64$ & $47.20 \pm 12.13 \mathrm{ab}$ \\
\hline BLePd & $24-72$ & $52.80 \pm 17.29 \mathrm{ab}$ \\
\hline BNIPTr & $32-64$ & $46.40 \pm 13.44 \mathrm{ab}$ \\
\hline BPM & $72-92$ & $80.80 \pm 7.69 \quad b$ \\
\hline $\mathrm{BPcPd}$ & $52-84$ & $67.20 \pm 14.25 \mathrm{ab}$ \\
\hline $\mathrm{BPcPd} 2$ & $32-64$ & $47.20 \pm 13.38 \mathrm{ab}$ \\
\hline $\mathrm{BTmPd}$ & $36-52$ & $44.80 \pm 7.15 \mathrm{ab}$ \\
\hline BTmSo & $32-76$ & $53.60 \pm 21.46 \mathrm{ab}$ \\
\hline $\mathrm{BTmTb}$ & $52-80$ & $54.40 \pm 16.63 \mathrm{ab}$ \\
\hline \multicolumn{3}{|c|}{ Metarhizium anisopliae } \\
\hline MaAgIn & $44-60$ & $53.60 \pm 6.69 \mathrm{ab}$ \\
\hline MagIn & $20-92$ & $47.20 \pm 29.03 \mathrm{ab}$ \\
\hline MagPd & $32-68$ & $48.00 \pm 16.73 \mathrm{ab}$ \\
\hline MaLaIn & $36-68$ & $49.60 \pm 13.73 \mathrm{ab}$ \\
\hline MLaPtr & $32-64$ & $42.40 \pm 17.57 \mathrm{a}$ \\
\hline $\mathrm{MTmBb}$ & $32-52$ & $44.80 \pm 7.69 \mathrm{ab}$ \\
\hline MTmBk & $52-60$ & $53.60 \pm 8.29 \mathrm{ab}$ \\
\hline $\mathrm{MTmGb}$ & $40-80$ & $54.40 \pm 15.3 \mathrm{ab}$ \\
\hline MtmIn & $36-64$ & $47.20 \pm 11.09 \mathrm{ab}$ \\
\hline MTmJr & $40-80$ & $57.60 \pm 10.43 \mathrm{ab}$ \\
\hline $\mathrm{MTmKj}$ & $28-88$ & $46.40 \pm 23.93 \mathrm{ab}$ \\
\hline MTmKt & $40-80$ & $56.80 \pm 14.80 \mathrm{ab}$ \\
\hline MTmMs & $32-68$ & $52.00 \pm 12.96 \mathrm{ab}$ \\
\hline MTmTk & $36-68$ & $50.40 \pm 15.12 \mathrm{ab}$ \\
\hline MTmTr & $36-56$ & $44.00 \pm 7.48 \mathrm{ab}$ \\
\hline
\end{tabular}

Data in the same column followed by the same letter showed they were not significantly different (HSD test, P 0.05). insects tended to be more difficult to be isolated. The other from the infected insects often were contaminated by air fungi. Hashim and Azwana (2003) reported that the conidia in the soil tended to be more persistent, they could be easily trapped using insect bait. Fuxa and Richter (2004) found that soils with high clay content improved persistence of the fungal conidia. Thus, future research using clay will be required to formulate the fungus conidia to increase efficacy as biological control.

Condial density observed were densed, and the highest conidial density of entomopathogenic fungi reached $45.39 \times 10^{6}$ conidia $\mathrm{mL}^{-1}$ that was found on $B$. bassiana isolates coded by BPcM. Soundarapandian and Chandra (2007) stated that conidial density were determined by mass production media and temperature of the incubated room. Liquid media tended to produce more conidia than those of solid ones. The optimum temperature and ideal $\mathrm{pH}$ for the mass production of $M$. anisopliae was found to be $25-30^{\circ} \mathrm{C}$ and 7 , respectively.

Few germinated conidia were observed at $24 \mathrm{~h}$ of incubation that only reached $47.50 \%$. The fungal isolates used in this study generally had low viability, it could be caused by shorter time ( $24 \mathrm{~h}$ ) used in incubation of conidial suspension. Conidia were considered germinated if germtube lengths were two times in diameter of the propagules or if with conspicuous swelling (Toledo et al. 2010). They reported that germinated conidia in vitro for $B$. bassiana and $M$. anisopliae at 72 hours could be $95.50 \%$ and $100 \%$, respectively. Bidochka et al. (2000) stated that

Table 5 Lethal time median $\left(\mathrm{LT}_{50}\right)$ of Aphis gossypii nymph exposed to conidia of Beauveria bassiana and Metharizium anisopliae at a concentration of $1 \times 10^{6}$ conidia $\mathrm{mL}^{-1}$

\begin{tabular}{|c|c|c|c|c|}
\hline \multirow{2}{*}{ Isolate codes } & \multirow{2}{*}{ Mean $\mathrm{LT}_{50}$ (days) } & \multicolumn{2}{|c|}{ 95\% Confidence limit } & \multirow{2}{*}{ Regression Equation } \\
\hline & & Lower & Upper & \\
\hline \multicolumn{5}{|c|}{ Beauveria bassiana } \\
\hline $\mathrm{BAgTb}$ & 3.18 & 2.97 & 3.50 & $y=0.176+0.066 x$ \\
\hline $\mathrm{BCcC}$ & 3.02 & 2.73 & 3.53 & $y=0.155+0.061 x$ \\
\hline BLePd & 2.91 & 2.69 & 3.23 & $\mathrm{y}=3.070+1.060 \mathrm{x}$ \\
\hline BNIPTr & 3.06 & 2.83 & 3.39 & $y=0.167+0.065 x$ \\
\hline BPM & 2.54 & 2.42 & 2.67 & $y=0.194+0.077 x$ \\
\hline $\mathrm{BPcPd} 1$ & 2.80 & 2.67 & 2.96 & $y=0.194+0.075 x$ \\
\hline BPcPD2 & 3.02 & 2.72 & 3.56 & $y=0.194+0.075 x$ \\
\hline BTmPd & 3.08 & 2.85 & 3.44 & $y=2.980+0.097 x$ \\
\hline BTmSo & 3.10 & 2.86 & 3.46 & $y=0.185+0.078 x$ \\
\hline $\mathrm{BTmTb}$ & 3.08 & 2.84 & 3.43 & $y=0.157+0.062 x$ \\
\hline \multicolumn{5}{|c|}{ Metarhizium anisopliae } \\
\hline MaAgIn & 2.81 & 2.56 & 3.21 & $y=0.142+0.058 x$ \\
\hline MAgIn & 3.03 & 2.78 & 3.42 & $y=2.890+0.950 x$ \\
\hline MAgPd & 3.02 & 2.75 & 3.47 & $y=0.188+0.079 x$ \\
\hline MaLaIn & 2.89 & 2.57 & 3.48 & $\mathrm{y}=0.144+0.058 \mathrm{x}$ \\
\hline MaLaPTr & 3.11 & 2.80 & 3.71 & $y=0.151+0.060 x$ \\
\hline $\mathrm{MTmBb}$ & 3.09 & 2.81 & 3.55 & $y=0.155+0.062 x$ \\
\hline MTmBk & 2.95 & 2.75 & 3.25 & $y=0.166+0.060 x$ \\
\hline MTmGb & 3.03 & 2.89 & 3.20 & $\mathrm{y}=3.060+1.010 \mathrm{x}$ \\
\hline MTmIn & 3.14 & 3.10 & 3.89 & $y=0.127+0.047 x$ \\
\hline MTmJr & 2.87 & 2.63 & 3.26 & $y=3.050+1.060 x$ \\
\hline $\mathrm{MTmKj}$ & 3.20 & 2.93 & 3.39 & $y=0.179+0.069 x$ \\
\hline MTmKt & 3.23 & 2.98 & 3.60 & $y=0.135+0.049 x$ \\
\hline MTmMs & 3.07 & 2.92 & 3.27 & $y=0.910+0.073 x$ \\
\hline MTmTk & 2.91 & 2.62 & 3.39 & $y=2.820+0.970 x$ \\
\hline $\mathrm{MTmTr}$ & 3.66 & 3.36 & 4.13 & $y=0.155+0.540 x$ \\
\hline
\end{tabular}


conidial viability was determined by temperature. The optimum temperature needed for entomopathogenic fungal conidia to germinate was $22-27^{\circ} \mathrm{C}$ with optimum humidity above $90 \%$, and at under $86 \%$ humidity, the virulence would decrease continuously.

Twenty five isolates of $B$. bassiana and $M$. anisopliae found in this reasearch were almost pathogenic againts A. gossypii nymphs. The most virulent isolate was BPM of $B$. bassiana isolate causing an average of $80.80 \%$ mortality. BPcM isolate was isolated from Chrysodeixis chalcites that was unrelated to A. gossypii. No relationship between pathogenicity and the origin of the isolates was observed. BagTb of B. bassiana isolate isolated from A. gossypii had the lowest pathogenicity and caused only $42.40 \%$ mortality of A. gossypii. Liu et al. (2002) also found that virulent isolates of $B$. bassiana or $M$. anisopliae could be originally isolated from related and unrelated hosts. The ability of the $\mathrm{BPcM}$ isolate to produce the highest mortality rates might be caused either by their genetic characteristics, or by their conidial viability. Aregger (1992) stated that conidial viability factor might be the factor affecting virulence. Rate of loss of conidial viability of $B$. bassiana varies among the strain. Decline of conidial viability of this fungus correlated with decline of host mortality due to its infection.

B. bassiana and M. anisopliae isolates needed just 2.54 days and 2.81 days, respectively to kill $A$. gossypii. It takes shorter time than they killed other species of host, such as planthopper Peregrinus maidis (Toledo et al. 2010). Thompson and Brandenburg (2005) reported that death caused by the fungi usually occured more than $48 \mathrm{~h}$ after attachment of conidia to the insect cuticle. Toledo et al. (2010) found that germ tubes on host cuticular surface began to be found at 24 and $48 \mathrm{~h}$, and they were observed penetrating directly through the host cuticle in regions near the hairs of the second antennal segment and on the laterosternites of abdomen. After $72 \mathrm{~h}$, long and errant germ tubes were detected on the cuticular surface. Fuxa and Richter (2004) stated that hyphae from M. anisopliae conidia entered the host's body with the help of enzymes or mechanical pressure. In the end, the host was covered all over with propagules and the soft parts of the body were penetrated so hyphal growth could be observed outside the host insect's body. External hyphal growth would produce conidia which spread spores into the environment upon reaching maturity, then infect other healthy insects. We concluded that $B$. bassiana and $M$. anisopliae were able to kill $A$. gossypii nymphs. Twenty five isolates of $B$. bassiana and $M$. anisopliae found were almost pathogenic againts them. The most virulent isolate was BPM of B. bassiana isolate causing an average of $80.80 \%$ mortality. Dead insect hosts infected by $M$. anisopliae showed the same symptoms as those infected by B. bassiana, except for the color of the hyphae which was greenish white.

\section{ACKNOWLEDGEMENTS}

We would like to thank Riyanto and Cheppy Wati for their assistance in the surveys. Financial support of this research was provided by the Project of Incentive Research Fund, Ministry of Research and Technology, Republic of Indonesia, Budget Year 2010 with Contract Number: 106/ RD-DF/D.PSIPTN/Insentif/PPK/1/2010, 15 January 2010.

\section{REFERENCES}

Alves SB, Rossi LS, Lopes RB, Tamai MA, Pereira RM. 2002. Beauveria bassiana yeast phase on agar medium and its pathogenicity against Diatraea saccharalis (Lepidoptera: Cerambidae) and Tetranychus urticae (Acari: Tetranychidae). J Invertebr Pathol 81:70-7.

Aregger E. 1992. Conidia production of the fungus Beauveria brongniartii on barley and quality evaluation during storage at $2^{\circ} \mathrm{C}$. J Invertebr Pathol 59:2-10.

Bidochka MJ, Kamp AM, Decroos JNA. 2000. Insect pathogenic fungi: from genes to populations. Fungal Pathol 42:171-93.

Feng MG, Chen C, Weishang SU, Ying SH, Shen ZC, Chen XX. 2007. Aphid dispersal flight disseminates fungal pathogens and parasitoids as natural control agents of aphids. Ecol Entomol 32:97-104.

Fuller SJ, Chavigny P, Lapchin L, Masutti FV. 1999. Variation in clonal diversity in glasshouse infestations of the aphid, Aphis gossypii Glover in Southern France. Mol Ecol 8:867-77.

Fuxa JR, Richter AR. 2004. Effects of Soil Moisture and Composition and Fungal Isolate on Prevalence of Beauveria bassiana in Laboratory Colonies of the Red Imported Fire Ant (Hymenoptera: Formicidae). Environ Entomol 33:975-81.

Hasyim A, Azwana. 2003. Pathogenicity of Beauveria bassiana (Balsamo) Vuillemin isolates in controlling of the banana weevil, Cosmopolites sordidus Germar. J Hort 13:120-30.

Herlinda S, Mulyati SI, Suwandi. 2008. Selection of isolates of entomopathogenic fungi, and the bioefficacy of their liquid production against Leptocorisa oratorius Fabricius nymphs. Microbiol Indones 2:1-5.

Herlinda S, Utama MD, Pujiastuti Y, Suwandi. 2006. Density and viability of spores of Beauveria bassiana (Bals.) Vuill. due to subcultures and media enriched, and its virulence against larvae of Plutellaxylostella(Linn.). JHPTT 6:70-8.

Klinger E, Groden E, Drummond F. 2006. Beauveria bassiana horizontal infection between cadavers and adults of the colorado potato beetle, Leptinotarsa decemlineata (Say). Environ Entomol 35:992-1000.

Liu H, Skinner M, Parker BL, Brownbridge M. 2002. Pathogenicity of Beauveria bassiana, Metarhizium anisopliae (Deuteromycotina: Hyphomycetes), and other entomopathogenic fungi against Lygus lineolaris (Hemiptera: Miridae). J Econ Entomol 95:675-81.

Lopes C, Spataro T, Lapchin L, Arditi R. 2009. Optimal release strategies for the biological control of aphids in melon greenhouses. Biol Contr 48:12-21.

Moraga EQ, Garcia AR, Alvarez CS. 2006. Laboratory evaluation of entomopathogenic fungi Beauveria bassiana and Metarhizium anisopliae against puparia and adults of Ceratitis capitata (Diptera: Tephritidae). J Econ Entomol 99:1955-66.

Santiago DR, Castillo AG, Arapan RS, Navasero MV, Eusebio JE. 2001. Efficacy of Metarhizium anasopliae (Metsch.) Sor. against the oriental migratoria locust, Locusta migratoria manilensis Meyen. Philipp Agric Sci 84:26-34.

Satar S, Kersting U, Uygun N. 1999. Development and fecundity of Aphis gossypii (Glover) (Homoptera: Aphididae) on three Malvaceae hosts. JAgric For 23:637-43.

Soundarapandian P, Chandra R. 2007. Mass production of endomopathogenic fungus Metarhizium anisopliae (Deuteromycota; Hyphomycetes) in the laboratory. Res J Microbiol 2:690-5.

Thompson SR, Brandenburg RL. 2005. Tunneling responses of mole crickets (Orthoptera: Gryllotalpidae) to the entomopathogenic fungus, Beauveria bassiana. Environ Entomol 34:140-7.

Toledo AV, Remes Lenicov AMM, López Lastra CC. 2010. Histopathology caused by the entomopathogenic fungi, Beauveria bassiana and Metarhizium anisopliae, in the adult planthopper, Peregrinus maidis, a maize virus vector. J Insect Sci 10:35. 10 p. [online]. http://www.insectsicence.org/10.35. [Sep 2010]. 
Wang KY, Liu TX, Yu CH, Jiang XY, Yi MQ. 2002. Resistance of Aphis gossypii (Homoptera: Aphididae) to fenvalerate and imidacloprid and activities of detoxification enzymes on cotton and cucumber. J Econ Entomol 95:407-13. 